Women and Birth

\title{
THE CHILDBIRTH EXPERIENCE: A SYSTEMATIC REVIEW OF PREDICTORS AND OUTCOMES
}

--Manuscript Draft--

\begin{tabular}{|c|c|}
\hline Manuscript Number: & WOMBI-D-20-00057R2 \\
\hline Article Type: & Review Article \\
\hline Keywords: & systematic review, childbirth experience, psychological trauma, women, positive birth \\
\hline Corresponding Author: & $\begin{array}{l}\text { Giliane McKelvin } \\
\text { Edge Hill University } \\
\text { Ormskirk, UNITED KINGDOM }\end{array}$ \\
\hline First Author: & Giliane McKelvin, BSc, PGC THE, MSc \\
\hline \multirow[t]{3}{*}{ Order of Authors: } & Giliane McKelvin, BSc, PGC THE, MSc \\
\hline & Gillian Thomson, PhD \\
\hline & Soo Downe, PhD \\
\hline Abstract: & $\begin{array}{l}\text { Background } \\
\text { Birth is often viewed as a pathological event, consequently, there has been an } \\
\text { increase in literature focusing on predictors, experience and implications of traumatic } \\
\text { childbirth and childbirth-related posttraumatic stress. However, to fully understand } \\
\text { childbirth experiences a salutogenic perspective is required. This enables an } \\
\text { understanding of what facilitates a positive childbirth experience besides what places } \\
\text { women at risk of experiencing traumatic childbirth. } \\
\text { Objective } \\
\text { To identify the psychosocial factors that could contribute to or be influenced by } \\
\text { women's subjective accounts of childbirth. } \\
\text { Method } \\
\text { An in-depth literature search across four databases was undertaken. Quality appraisal } \\
\text { based on internal and external validity was conducted and a combined numerical } \\
\text { summary and categorical description were undertaken. } \\
\text { Findings } \\
\text { Nineteen papers were included in the review and the variables grouped into three } \\
\text { categories. The variables relate to 'Measures of labour and birth experience' } \\
\text { (discussing the impact of events and perceptions during labour and birth). The second } \\
\text { category discusses how 'support and relationships' can potentially shape the birth } \\
\text { experience or be altered by it and finally, 'Psychological variables: influence and } \\
\text { impact' is examined extensively. } \\
\text { Discussion } \\
\text { The results of the review highlight significant contradictory evidence of what influences } \\
\text { birth experiences. The findings confirm the dearth of available literature concerning } \\
\text { positive birth experiences and most variables identified were pathogenic. This } \\
\text { review suggests that such factors for PTSD may differ from those that influence birth } \\
\text { experiences and should be examined separately. An enhanced understanding of the } \\
\text { range of experiences is required to support women's rights in achieving a positive birth. }\end{array}$ \\
\hline Response to Reviewers: & A table has been added as requested. \\
\hline
\end{tabular}


$12^{\text {th }}$ April 2020

Dear Prof Caroline Homer,

We wish to submit a review article entitled "The Childbirth Experience: A Systematic Review of Predictors and Outcomes" for consideration by Women and Birth. We confirm that this work is original and has not been published elsewhere, nor is it currently under consideration for publication elsewhere. All authors have reviewed and approved the attached manuscript and abide by the copyright terms of Elsevier and the Australian College of Midwives. We have no conflicts of interest to disclose. Ethical approval was not required for this review and no source of funding was used.

In this paper, we present a review of predictors and outcomes associated with different birth experiences, however, as the review portrays there appears to a be a significant focus on the research of traumatic birth experiences when compared to positive birth. There also appears to be a focus on pathogenic influencing factors and outcomes with a poor understanding of salutogenic variables. Subsequently, this does not capture the range of events, experiences and emotions that can influence birth experience or how women may experience the birth which can limit health professionals' understanding of how women can be supported to achieve a positive birth.

We believe that this manuscript is appropriate for publication by Women and Birth because it is specifically focused on birth experiences, what shapes these experiences for women and the aftermath. At a time when focus on pathogenesis continues to grow and positive birth experiences being considered women's right, it is timely to highlight the need to expand our horizon by having a full understanding of what can shape such an experience.

Thank you for your consideration of this manuscript.

Sincerely,

Giliane McKelvin 
Response to Reviewers (without Author Details)

THE CHILDBIRTH EXPERIENCE: A SYSTEMATIC REVIEW OF PREDICTORS AND OUTCOMES

\section{Second Review}

A table has been added to briefly show what tools have been used to examine each variable. 


\section{THE CHILDBIRTH EXPERIENCE:} A SYSTEMATIC REVIEW OF PREDICTORS AND OUTCOMES

Giliane McKelvin, MSc, $\mathrm{RM}^{1,3}$

Dr Gillian Thomson, $\mathrm{PhD}^{2}$

Prof Soo Downe, $\mathrm{PhD}^{2}$

${ }^{1}$ Department of Nursing and Midwifery, Edge Hill University, UK

${ }^{2}$ School of Community Health and Midwifery, University of Central Lancashire, UK

${ }^{3}$ Corresponding Author: Giliane McKelvin, Edgehill University, St Helens Road, Ormskirk, L39 4QP. Tel: 01695657046. Email: fenechg@edgehill.ac.uk 


\section{A SYSTEMATIC REVIEW OF PREDICTORS AND OUTCOMES}

Problem: birth is often explored from either a positive or traumatic perspective, whereas the continuum of childbirth experiences (positive, neutral and traumatic birth experiences) is yet to be considered.

What is already known: traumatic and positive birth can be influenced by various factors such as perception of control during labour and the perceived support of the midwife. The influences of a traumatic birth are also well-known including depression, anxiety and post-traumatic stress disorder.

\section{What this paper adds:}

1. There is a focus on the impact and influences of traumatic birth, and further consideration to positive and neutral birth is needed.

2. When exploring birth experiences, the focus is on pathogenic factors such as ill-health, with less understanding of how salutogenic factors such as mental wellbeing impacts birth experiences.

3. The influencing factors for post-traumatic stress disorder and negative birth experiences are not necessarily the same and thus these two different issues should be explored separately.

\section{Introduction}

Childbirth is considered to be a 'significant event of powerful psychological importance in a woman's life' (Nichols, 1996, p.71). Humenick (2006) claimed that birth can represent a 'flow experience' which challenges women to grow and change in a life-expanding manner. According to Csikszentmihalyi, (1990) flow experiences can make individuals feel in control and masters of their fate, providing a sense of exhilaration and a deep sense of enjoyment that becomes a landmark memory for what a peak life 
experience could be. However, recent literature has identified that some women can experience childbirth as a distressing, traumatic event, leading to post-traumatic stress disorder (PTSD) onset (Creedy et al., 2000) and other psychological morbidities (Skari et al., 2002; Elmir et al., 2010; Anderson et al., 2012; Grekin \& O’Hara, 2014; Fenech \& Thomson, 2014; Ayers et al., 2016; Yildiz et al., 2017).

It has been suggested that between $20 \%$ and $48 \%$ of women experience a traumatic birth (Ayers et al., 2009), with $4 \%$ and $18.5 \%$ of women in the community (i.e. low risk) and 'at risk' (e.g. history of mental illness) populations respectively develop PTSD following childbirth (Yildiz et al., 2017). There is some evidence which suggests that risk factors for childbirth trauma relate to unexpected medical problems; including an emergency operative or assisted delivery (Waldenstrom et al., 2004), unmet expectations (O'Donovan et al., 2014), poor perceived control in labour (Goodman et al., 2004) and trait anxiety and a history of sexual abuse (Boorman et al., 2014). The risk factors of PTSD have been explored further. A meta-analysis including 50 papers that focuses on the aetiology of PTSD following childbirth, indicates that pre-birth vulnerability factors most strongly associated with PTSD were depression, fear of childbirth, complications during pregnancy, and a history of PTSD and counselling, as well as having an operative or negative birth, and lack of support and dissociation during birth (Ayers et al., 2016). Furthermore, following a traumatic birth, women can develop post-traumatic stress symptoms (PTSS, Creedy et al., 2000), experience suicidal thoughts (Howard et al., 2011) and depression (Bener et al., 2012). A traumatic birth can also influence subsequent pregnancies and childbirth due to tokophobia (Hofberg \& Brockington, 2000; Waldenstrom et al., 2004). PTSD has been associated with dysfunctional defence mechanisms (Fenech \& Thomson, 2014), parenting stress, poor parent-child relationships (McDonald et al., 2011), and relationship problems with partners (Ayers et al., 2007) including sexual dysfunction (Ayers et al., 2006). Some authors (Zeanah et al, 1999 in Benoit, 2004) also report that women suffering from PTSD may witness behavioural problems and emotional maladjustment in children. 
As is apparent from the literature cited in this introduction, research in this area predominantly focuses

This lack of knowledge and understanding of what promotes health is to such an extent that childbirth is sometimes viewed as a pathological event (Davis \& Walker, 2013). However, to fully understand childbirth, factors that promote positive experiences and risk factors for traumatic birth both need to be explored. Health needs to be explored systematically along the health continuum, which eliminates the distinct dichotomy of being in a state of health or disease. Similarly, to obtain a thorough understanding of childbirth experiences, negative childbirth cannot be explored by itself, but positive childbirth experiences require equal attention. This relates to Antonovsky's concept of salutogenesis in which he explained that by taking a salutogenic orientation and focusing on the origins of health, instead of disease and pathology alone, health professionals will be able to explore why individuals are located at the positive end of the health ease/dis-ease continuum or why they move towards the positive end of the continuum. It enables one to think in terms of factors which promote movement towards the healthy 
end of the continuum and opens the way for considering stressors which have positive health consequences (Antonvosky, 1987).

The salutogenic framework (Mittelmark et al., 2007) provides a useful lens to obtain a thorough understanding of women's subjective birth experiences. Thus, both positive and traumatic childbirth experiences need to be explored. This will create an understanding of what facilitates a positive childbirth experience (protective factors) and equally, an understanding of what places women at risk of experiencing traumatic childbirth (risk factors).

\subsection{Aims and objectives}

The review aimed to identify the psychosocial factors that could contribute to, or be influenced by women's subjective accounts of childbirth (i.e. positive, traumatic).

The objectives were:

1. To identify psychosocial variables which have been reported to predict women's perceptions (i.e. positive, traumatic) of childbirth

2. To identify which postnatal psychosocial variables have been shown to be influenced by women's perceptions of the birth experience

For this study, it was considered vital to include studies that examined psychosocial variables concerning PTSD since it is highly likely that women who develop PTSD following childbirth had a negative birth experience. For the purpose of this paper, childbirth includes any mode of delivery, i.e. vaginal, instrumental or surgical. While complications during childbirth such as instrumental birth were considered in this paper, only women with no pregnancy complications and a healthy foetus/infant were considered as it is recognised that women who experience a fetal or neonatal loss, are expecting a compromised infant or experience NICU admissions, and experience pregnancy complications are likely to suffer from psychological morbidities such as anxiety and depression (Georgsson Öhman et 
al., 2006; Kelley \& Trinidad, 2012; Downe et al., 2013; Hsieh, Chao \& Shiao, 2013) which can subsequently influence childbirth experiences.

\section{Methods}

A systematice review was undertaken for this study.

\subsection{Search strategy}

The initial searches were undertaken between April and June 2015, and repeated in December 2018, in CINAHL, MEDLINE, PsychINFO and COCHRANE, with no date restrictions. The PEO (population, exposure and outcome) framework was used to guide the search strategy as opposed to the PICO (population, intervention, comparison, outcome) since the purpose of this review was not to explore specific interventions (Bettany-Saltikov, 2012). Outcomes were selected by identifying psychosocial outcome terms available from each database. Search terms (Table 1), were piloted (i.e. any search terms that yielded no results were removed) and adjusted according to the subject terms available for each database before formal searches being undertaken.

\begin{tabular}{ll}
\hline Terms \\
\hline Population & wom?n, mother*, maternal \\
\hline Exposure & pregnan*, antenatal, expecting, childbearing, puerperium, postnatal, \\
& postpartum, childbirth, birth, parturition, lab?r, delivery, intrapartum \\
\hline Outcome & life events, personality traits, sense of coherence, psycho*, anxiety, \\
& depression, post-traumatic stress disorder, PTSD, trauma*, social support, \\
& stress, relation*, attachment, bonding, emotional, behavi?r, tokophobia, \\
& sexual*, *feeding, quality of life, cognitive
\end{tabular}

Table 1 - Search terms used

Wildcard symbols and truncations were used in line with database requirements. MESH terms were used for MEDLINE where appropriate. 


\subsection{Inclusion and exclusion criteria}

Table 2 sets out the inclusion and exclusion criteria.

\begin{tabular}{|c|c|c|}
\hline & Inclusion Criteria & Exclusion Criteria \\
\hline Participants & $\begin{array}{l}\text { Women with no pregnancy } \\
\text { complications who are } \\
\text { expecting or had a healthy } \\
\text { term baby }\end{array}$ & $\begin{array}{l}\text { Women who are expecting a } \\
\text { compromised baby or had preterm, } \\
\text { stillbirth or a baby who was admitted to } \\
\text { the Neonatal Intensive Care Unit } \\
\text { (NICU) } \\
\text { Women's partners and family members } \\
\text { (when included on their own) } \\
\text { Women with pregnancy complications }\end{array}$ \\
\hline Exposure & $\begin{array}{l}\text { - Study includes mostly* } \\
\text { valid and reliable } \\
\text { quantitative tools to assess } \\
\text { psychosocial variables and } \\
\text { the childbirth experience }\end{array}$ & $\begin{array}{l}\text { - Study includes mostly quantitative } \\
\text { tools which have not been validated } \\
\text { - Study only includes interviews, } \\
\text { narrative accounts or observations } \\
\text { - Effectiveness studies of drugs or } \\
\text { therapy to influence psychosocial } \\
\text { variables }\end{array}$ \\
\hline Outcome & $\begin{array}{l}\text { Psychosocial wellbeing } \\
\text { across the perinatal period } \\
\text { in relation to the birth } \\
\text { experience and/or PTS }\end{array}$ & $\begin{array}{l}\text { - Focus only on physical health during } \\
\text { pregnancy and postnatally } \\
\text { - Focus only on physical } \\
\text { implications/outcomes of labour and } \\
\text { childbirth }\end{array}$ \\
\hline
\end{tabular}


- Cause and effect studies assessing the association between specific intrapartum events (such as type of birth) on psychosocial wellbeing across the perinatal period

- The experience of childbirth

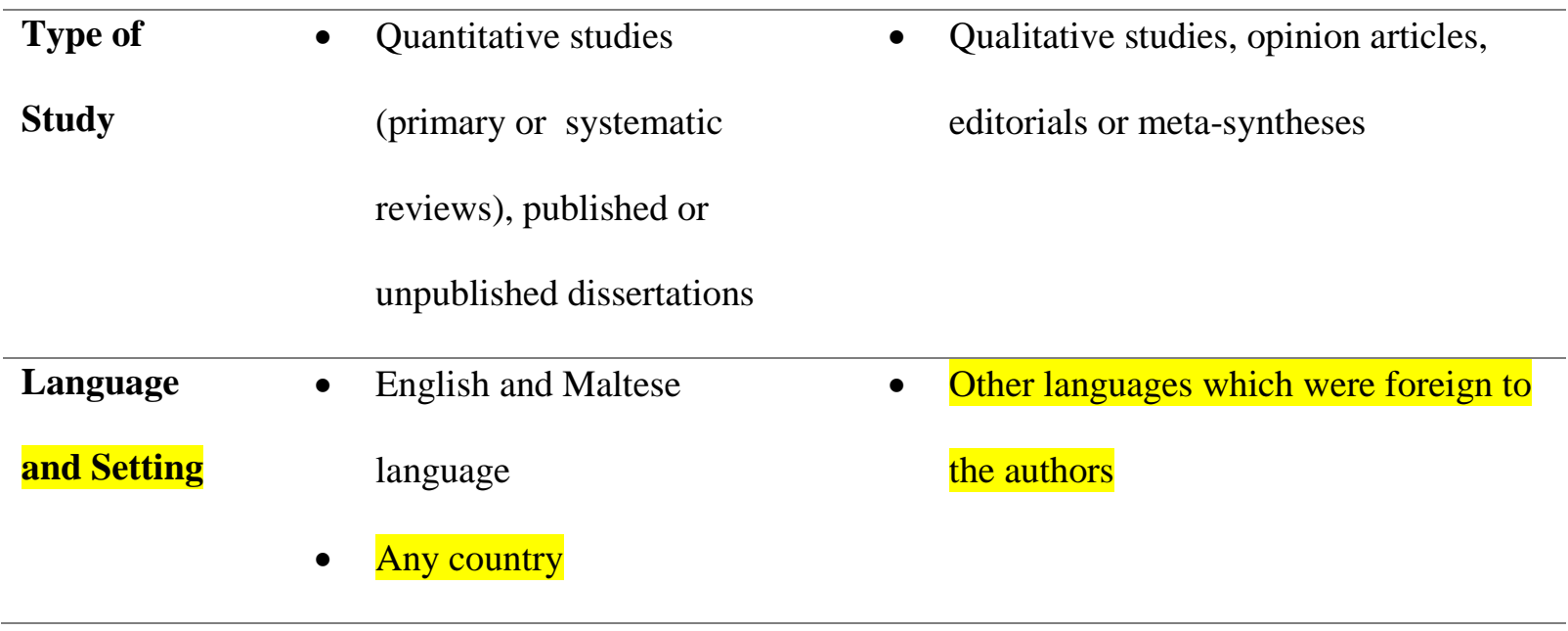

Table 2 - Inclusion and exclusion criteria

\section{*defined as over $50 \%$ for this review}

The initial stage of the literature selection process was carried out by members of the author team, all having previous review experience. All abstracts were assessed for inclusion and when all criteria were met or if this could not be determined from the abstract, the full text was obtained for a full assessment. Studies which met the inclusion criteria had their citations and references checked for additional relevant papers. Any studies selected for full-text review or excluded based on one criterion were double-checked by another team member to ensure agreement. When research papers were not available or their compliance with the selection criteria remained unclear, the authors were contacted. Research studies for which the full text was unobtainable after this process or if their compliance could not be determined (ex: due to language barrier) were excluded from the analysis, but classified as a 'potentially relevant study'. All studies that met the inclusion criteria proceeded to quality appraisal. 


\subsection{Quality appraisal}

Sanderson et al (2007) in a review to assess tools available for observational studies despite making no suggestions of specific tools, recommended that 'tools should (i) include a small number of key domains; (ii) be as specific as possible (with due consideration of the particular study design and topic area); (iii) be a simple checklist rather than a scale and (iv) show evidence of careful development, and of their validity and reliability' (pg.674). The National Institute for Health and Care and Excellence (NICE) checklist for quantitative studies reporting correlations and associations which was built on the Graphic Appraisal Tool for Epidemiological studies (GATE) framework (Jackson et al, 2006) was adopted for quality appraisal as it was suitable for observational studies and met all of Sanderson et al's (2007) criteria. The NICE checklist tool used generated a quality score for internal validity $(++,+,-)$ and a separate score for external validity $(++,+,-)$. To ensure consistency and transparency throughout the appraisal process, a single rating ('A' to 'D') was created by the authors from the two quality scores (Table 3). The internal validity score is based on three separate sections with nine questions [as opposed to one section with three questions examining external validity], thus the internal validity was given a stronger bearing when creating the table.

\begin{tabular}{|l|l|l|l|}
\hline Internal Validity & ++ & + & - \\
\hline External Validity & & & \\
\hline++ & A & B & C \\
\hline+ & A & B & D \\
\hline- & B & C & D \\
\hline
\end{tabular}

Table 3 - Quality appraisal scores based on internal and external validity

++ All or most of the checklist criteria have been fulfilled, where they have not been fulfilled the conclusions are very unlikely to alter.

+ Some of the checklist criteria have been fulfilled, where they have not been fulfilled, or not adequately described, the conclusions are unlikely to alter. 


\subsection{Analysis and synthesis}

As this review contained non-randomised control trials, a meta-analysis was not appropriate. A combined numerical summary and categorical description were undertaken to address the objectives. The variables that measured similar/related issues were grouped into categories, and the number of papers that reported on the variables documented. The results presented in this paper categorise and discuss which independent variables (e.g. personality traits, parity, social support, the birth experience) predict (or not) the dependent variables (e.g. the birth experience, postnatal depression, couple's relationship).

\section{Results}

\subsection{Study selection and characteristics}

The PRISMA diagram (Figure 1) provides an overview of the search strategy. Overall, 10,115 hits were identified, and nineteen papers met all the review criteria and were included (Table 4). The studies were published between 2000 and 2014, were undertaken in high-income countries, and explored 28 different variables. A total of 8,775 individuals participated in the studies and included primiparous and multiparous women, women from diverse ethnic/educational backgrounds and with varying relationship status. The time frame of data collection differed with data collected at varying points during the pregnancy (as early as 18 weeks) and postnatally (i.e. one day to five years post-natal). Methods were largely cohort studies, and the quality was variable, with the main quality issues relating 
to minimising risk of bias as potential confounders were not controlled for and lack of generalisability to the source population.

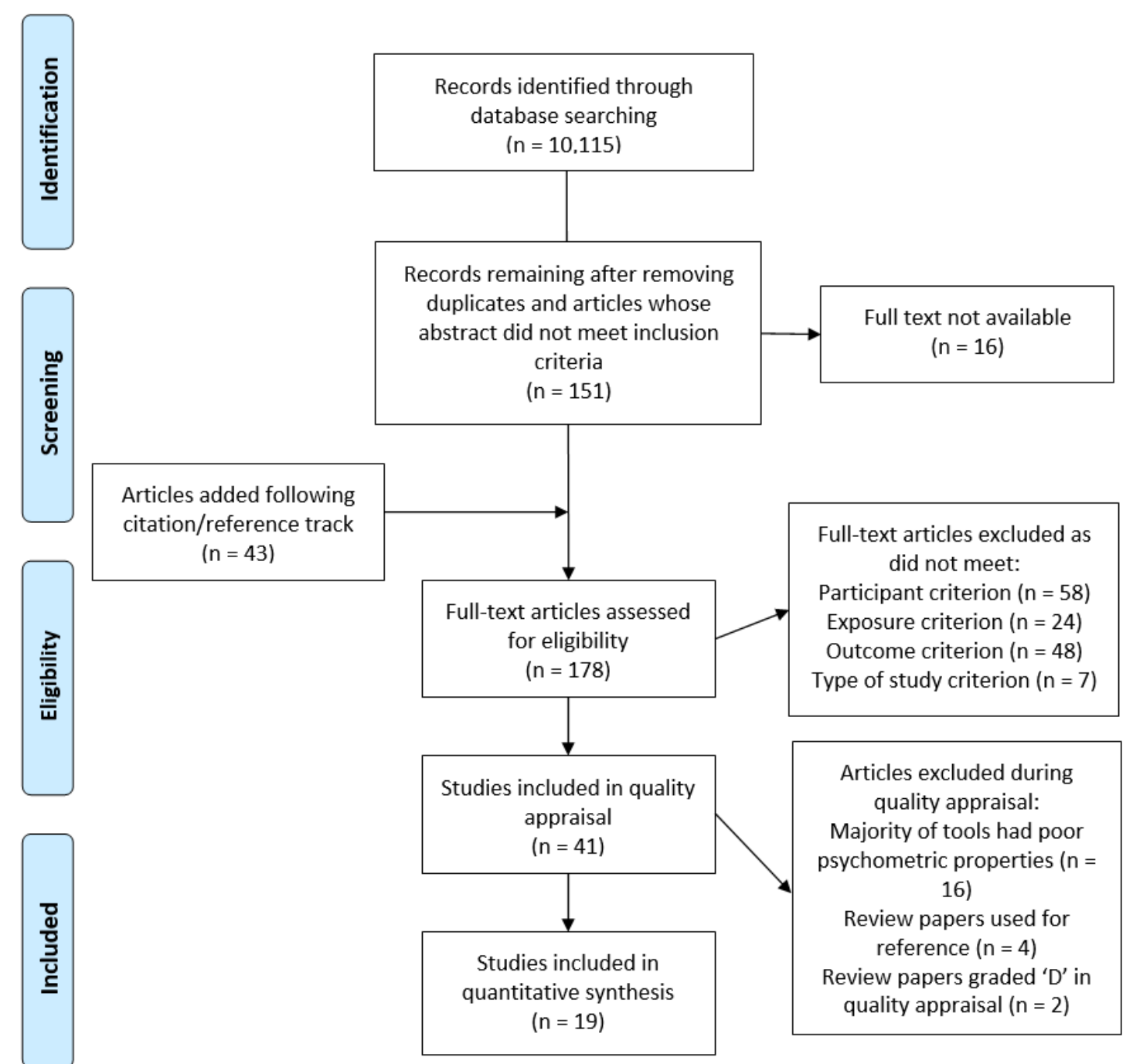

Figure 1 - Prisma Diagram

\begin{tabular}{lllll}
\hline Authors (Year) & Country & Study design & Sample & Quality \\
& & Retrospective, cohort, & 64 couples & C \\
Ayers, Wright \& & England & correlational study & \\
Wells (2007) & & Prospective, longitudinal study & 57 women & C \\
\hline Ayers et al (2014) & England & Retrospective, cross-sectional, & 300 women & C \\
\hline Bennington (2010) & USA & correlational study & \\
& & & &
\end{tabular}




\begin{tabular}{|c|c|c|c|c|}
\hline Boorman et al (2014) & Australia & $\begin{array}{l}\text { Cross-sectional exploratory } \\
\text { study }\end{array}$ & 890 women & B \\
\hline Bryanton et al (2008) & Canada & Prospective cohort study & 175 women & $\mathrm{B}$ \\
\hline Carlander et al (2014) & Sweden & Prospective cohort study & 451 women & A \\
\hline Cohen et al (2004) & Canada & Correlational cohort study & 200 women & $\mathrm{C}$ \\
\hline $\begin{array}{l}\text { Creedy, Shochet \& } \\
\text { Horsfall (2000) }\end{array}$ & Australia & Prospective cohort study & 592 women & $\mathrm{B}$ \\
\hline $\begin{array}{l}\text { Czarnocka \& Slade } \\
\text { (2000) }\end{array}$ & England & Exploratory study & 264 women & $\mathrm{C}$ \\
\hline Davies et al (2008) & England & Exploratory study & 211 women & $\mathrm{B}$ \\
\hline Edworthy et al (2014) & England & Prospective cohort study & 121 women & $\mathrm{B}$ \\
\hline $\begin{array}{l}\text { Ford, Ayers \& } \\
\text { Bradley (2010) }\end{array}$ & England & Longitudinal cohort study & 138 women & $\mathrm{B}$ \\
\hline $\begin{array}{l}\text { Goodman, Mackey \& } \\
\text { Tavakoli (2004) }\end{array}$ & USA & Correlational descriptive study & 60 women & $\mathrm{B}$ \\
\hline Larsson et al (2011) & Sweden & Cohort study & 541 women & $\mathrm{B}$ \\
\hline $\begin{array}{l}\text { Leeds \& Hargreaves } \\
\text { (2008) }\end{array}$ & Wales & Retrospective correlational study & 102 women & B \\
\hline Lukasse et al (2010) & Norway & Cross-sectional study & $\begin{array}{l}2,365 \\
\text { women }\end{array}$ & A \\
\hline Olde et al (2005) & Netherlands & Correlational study & 140 women & A \\
\hline White et al (2006) & Australia & Cohort study & 261 women & B \\
\hline Weisman et al (2010) & Israel & Cohort study & $\begin{array}{l}1,844 \\
\text { women }\end{array}$ & $\mathrm{B}$ \\
\hline
\end{tabular}




\subsection{Findings}

Twenty-five of the 28 variables explored by the studies were psychosocial and therefore relevant to the aims and objectives of this review. The studies explored the psychosocial variables as either predictors or outcomes, dependent on the design and methodology of each study. Eight studies focused on predictor variables, five studies on outcome variables and six studies made use of both.

Only one study examined the relationship between psychosocial variables and women's experiences of labour and birth in relation to a positive birth experience. The rest of the included studies adopted a more pathogenic perspective. Six explored psychosocial variables in relation to a negative birth experience (either being pre-defined by the participants or characterised as negative for women who scored less than or equal to 5 on a 10-point likert scale rating their birth experience) and 12 examined the relationship between psychosocial variables and the development and maintenance of PTSS. The included studies made use of various analytical methods ranging from simple descriptive statistics to more complex regression analyses.

From the outset, it was evident that there were limited positive factors explored in the included studies. Additionally, some factors appeared to play a role across different time frames of the childbearing period. Thus, the findings were presented into categories relating to the event, social and psychological factors to avoid unnecessary complications. This includes: 'Measures of labour and birth experience', 'Outcomes of support and relationships' and 'Psychological variables: influence and impact'. The first category focused on factors relating to the time and event of the birth itself, the second category focused on social factors and the third category on psychological factors. Within each category predictor and outcome, variables were identified. An overview of the variables explored within each category is presented in Table 5 and the tools used to examine such variables is presented in Table 6 . 


\section{Table 5 - Overview of findings within each category}

Variable Questionnaire Used in

\begin{tabular}{|c|l|l|}
\hline \multirow{4}{*}{$\begin{array}{c}\text { History Of } \\
\text { Traumatic }\end{array}$} & The PTSD Diagnostic Scale & Ford et al., (2010) \\
\cline { 2 - 3 } Experiences & The National Comorbidity Survey & Cohen et al., (2004) \\
\cline { 2 - 3 } And Abuse & The Revised Conflicts Tactics Scale & Cohen et al., (2004) \\
\cline { 2 - 3 } & Abuse Assessment Screen & Cohen et al., (2004) \\
\cline { 2 - 3 } & $\begin{array}{l}\text { Canadian Violence Against Women } \\
\text { Survey }\end{array}$ & Cohen et al., (2004) \\
& Surve & \\
\hline
\end{tabular}




\begin{tabular}{|c|c|c|}
\hline \multirow[t]{2}{*}{ Expectations } & $\begin{array}{l}\text { The Perceptions of Labour and Delivery } \\
\text { Questionnaire }\end{array}$ & $\begin{array}{l}\text { Leeds \& Hargreaves, } \\
\text { (2008); Czarnocka \& Slade, } \\
\text { (2000) }\end{array}$ \\
\hline & The Experience of Birth Scale & Ayers et al., (2007) \\
\hline \multirow{5}{*}{$\begin{array}{c}\text { Perceptions of } \\
\text { Pain }\end{array}$} & McGill Pain Questionnaire & Goodman et al., (2004) \\
\hline & $\begin{array}{l}\text { The Perceptions of Labour and Delivery } \\
\text { Questionnaire }\end{array}$ & Czarnocka \& Slade (2000) \\
\hline & The Experience Of Birth Scale & Ayers et al., (2007) \\
\hline & $\begin{array}{l}\text { The Perceptions Of Labour and Delivery } \\
\text { Ouestionnaire }\end{array}$ & $\begin{array}{l}\text { Czarnocka \& Slade (2000); } \\
\text { Leeds \& Hargreaves, (2008) }\end{array}$ \\
\hline & The Peritraumatic Emotions List & Olde et al., (2005) \\
\hline \multirow{2}{*}{$\begin{array}{l}\text { Care During } \\
\text { Labour }\end{array}$} & The Perception Of Care Questionnaire & Creedy et al.,(2000) \\
\hline & $\begin{array}{l}\text { The Perceptions Of Labour and Delivery } \\
\text { Questionnaire }\end{array}$ & $\begin{array}{l}\text { Czarnocka \& Slade (2000); } \\
\text { Leeds \& Hargreaves, (2008) }\end{array}$ \\
\hline \multirow[t]{2}{*}{ Dissociations } & $\begin{array}{l}\text { The Peritraumatic Dissociative } \\
\text { Experiences Questionnaire - Self Report } \\
\text { Version }\end{array}$ & Olde et al., (2005) \\
\hline & $\begin{array}{l}\text { Somatoform Dissociation Questionnaire - } \\
\text { Peritraumatic }\end{array}$ & Olde et al, (2005) \\
\hline \multirow{4}{*}{$\begin{array}{l}\text { Perceptions Of } \\
\text { Control }\end{array}$} & The Perceived Control Scale & $\begin{array}{l}\text { Czarnocka and Slade, } \\
\text { (2000) }\end{array}$ \\
\hline & The Labour Agentry Scale & Goodman et al., (2004) \\
\hline & Experience of Birth Scale & Ayers et al., (2007) \\
\hline & $\begin{array}{l}\text { The Perceptions Of Labour and Delivery } \\
\text { Questionnaire }\end{array}$ & $\begin{array}{l}\text { Leeds and Hargreaves, } \\
\text { (2008) }\end{array}$ \\
\hline \multirow{4}{*}{ Social Support } & The Significant Others Scale - Version A & Edworthy et al., (2010) \\
\hline & $\begin{array}{l}\text { Support And Control During Birth } \\
\text { Questionnaire }\end{array}$ & Ayers et al., (2014) \\
\hline & $\begin{array}{l}\text { The Medical Outcomes Social Support } \\
\text { Survey }\end{array}$ & Ford et al., (2010) \\
\hline & The Perception Of Care Questionnaire & Creedy et al.,(2000) \\
\hline
\end{tabular}




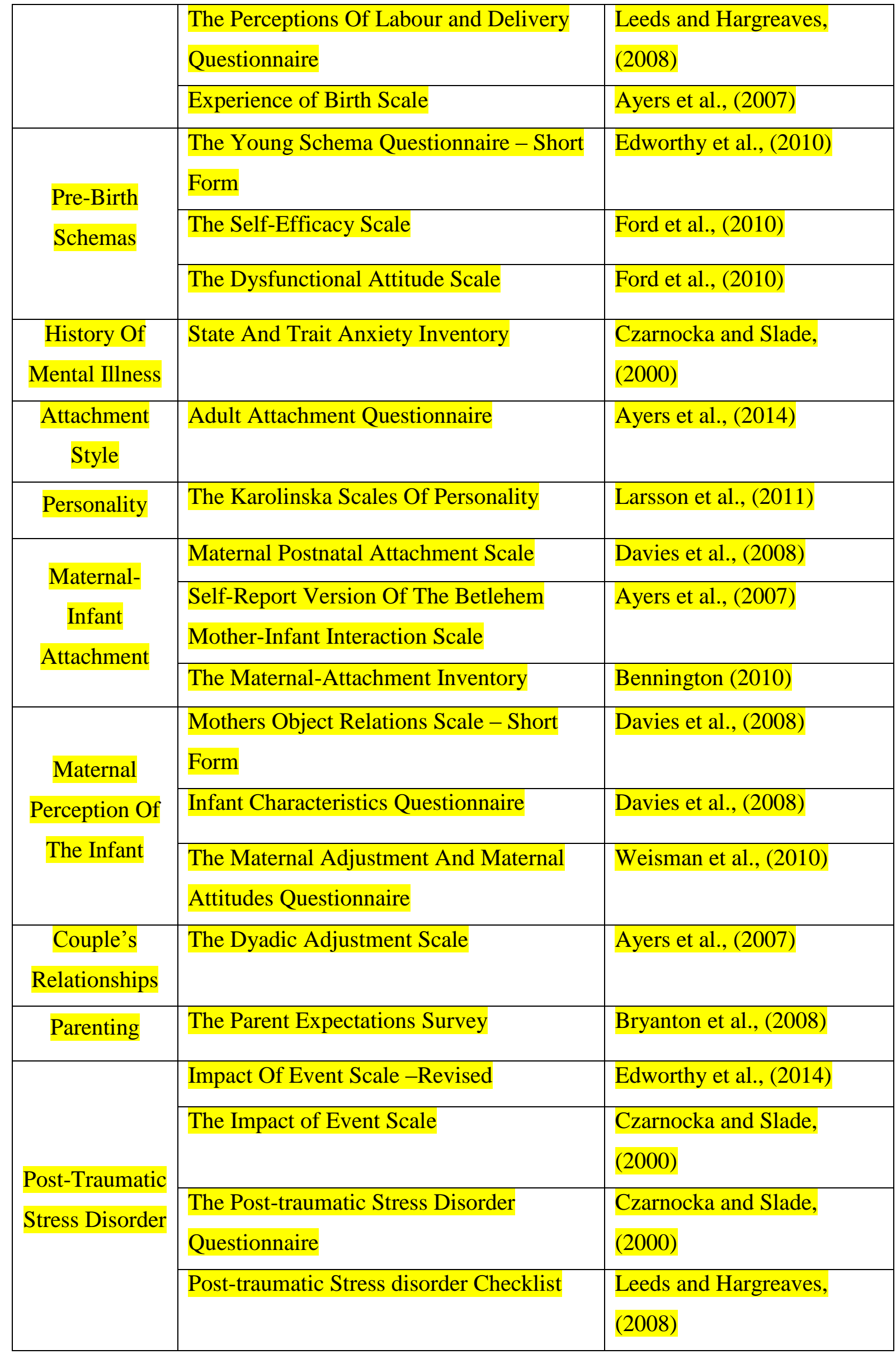




\begin{tabular}{|c|c|c|}
\hline \multirow{9}{*}{$\begin{array}{l}\text { Postnatal } \\
\text { Depression }\end{array}$} & The Beck Depression Inventory & Weisman et al; (2010) \\
\hline & The Edinburgh Postnatal Depression Scale & Czarnocka and Slade \\
\hline & & (2000); Cohen et al., (2004); \\
\hline & & White et al., (2006); \\
\hline & & Edworthy et al., (2008); \\
\hline & & Davies et al., (2008); Leeds \\
\hline & & and Hargreaves, (2008); \\
\hline & & Boorman et al., (2014) \\
\hline & $\begin{array}{l}\text { Depression, Anxiety And Stress Scale } 21 \\
\text { Short Form }\end{array}$ & Boorman et al., (2014) \\
\hline \multirow{3}{*}{$\begin{array}{l}\text { Postpartum } \\
\text { Anxiety }\end{array}$} & Depression, Anxiety And Stress Scale 21 & Boorman et al., (2014) \\
\hline & Short Form & \\
\hline & State And Trait Anxiety Inventory & $\begin{array}{l}\text { Czarnocka and Slade, } \\
(2000)\end{array}$ \\
\hline
\end{tabular}

Table 6 - Overview of tools used to examine each variable

\section{Measures of labour and birth experience}

Five predictor variables were included in this category, relating to women's perceptions of pain during labour, their emotions during the birth, the care they received during labour, and their perception of control and dissociation during labour.

Negative affective states such as horror, powerlessness, embarrassment and guilt (Olde et al., 2005; Ayers, Wright \& Wells, 2007); fear for self (Czarnocka \& Slade, 2000) or fear for baby (Leeds \& Hargreaves, 2008); and blame (Czarnocka \& Slade, 2000) were risk factors for PTSD onset post-birth, but not for negative birth experiences. Olde et al., (2005) also explored the relationship between peritraumatic dissociation and postpartum PTSD. Two types of dissociations; psychoform phenomenon (dissociative amnesia and identity fragmentation) or somatoform phenomenon (dissociative symptoms that phenomenologically involve the body such as the inability to speak or move) were examined and concluded that both types of dissociation significantly predicted PTSD symptoms. 


\section{Social support and relationships}

The second category explored how support and relationships can potentially both influence or are influenced by women's birth appraisals and PTSD onset. One predictor variable; social support and four outcome variables; maternal-infant attachment, the mother's perception of the infant; the couple's relationship; and their parenting self-efficacy were identified in this category.

The papers included in this review suggest that PTSS and a negative birth experience negatively influence women's perception of their infant; viewing them as less warm (Davies et al., 2008) and having more negative emotions towards them (Weisman et al., 2010) respectively. However, neither parenting (Bryanton et al., 2008) nor the couple's relationship (Ayers et al., 2007) were impacted. It is also suggested that while the birth experience may have a positive influence on the mother-infant bond, (even though further research was recommended, Bennington, 2010), PTSD does not (Ayers et al., 2007; Davies et al., 2008). While a few authors suggest that lack of support from health professionals (Czarnocka \& Slade, 2000; Larsson et al., 2011) or partners (Creedy et al., 2000; Czarnocka \& Slade, 2000) place women at a higher risk of negative birth experience or PTSS, others (Cohen et al., 2004; Ayers et al., 2007; Edworthy et al., 2008; Ayers et al., 2014) reported that this was not the case. 
However, the fact that some studies did not use validated scales, and had wide variations in sample sizes may explain the contradictory data.

\section{Psychological variables: influences and impact}

The predictor variables in this category included the impact of parity, history of mental illness, previous experiences of trauma and abuse, expectations, pre-birth schemas, and attachment and personality traits on the birth experience and PTSD. The outcome variables of subsequent pregnancies, fear of childbirth, anxiety, PTSD and postnatal depression (PND) and how they were influenced by the birth experience [and PTSD] following childbirth were also explored.

The included papers strongly suggest that pre-birth schemas such as impaired limits (the inability to cooperate or form commitments with others or to meet personal goals) (Edworthy et al., 2008), dysfunctional attitudes (Ford et al., 2010) and worrying during pregnancy (Larsson et al., 2011) put women at increased risk of developing PTSS and negative birth experience. Avoidant attachment (Ayers et al., 2014) and irritation personality trait (Larsson et al., 2011) also pose the same risks. A history of sexual abuse did not influence PTSS onset (Cohen et al., 2004; Boorman et al., 2014). Apart from a traumatic birth being identified as a risk factor for PTSS onset (Czarnocka \& Slade, 2000; Edworthy et al., 2008; Leeds \& Hargreaves, 2008), it was also found to be associated with postnatal depression and anxiety (Weisman et al., 2010, Boorman et al., 2014), and fear of childbirth (Lukasse et al., 2010). Other authors (Czarnocka \& Slade, 2000; Cohen et al., 2004; White et al., 2006; Davies et al., 2008; Edworthy et al., 2008; Leeds \& Hargreaves, 2008) also report significant comorbidity between PND and PTSD.

Contradictory evidence was identified regarding other variables in this category. While there were differences between the studies in regard to the impact of a history of mental illness, the response rate could be an explanation. Studies (Czarnocka \& Slade, 2000; Cohen et al., 2004; Boorman et al., 2014) that found a positive correlation with a history of mental illness, all report a response rate above $74 \%$, 
whereas other studies (Edworthy et al., 2008; Leeds and Hargreaves, 2008 respectively) which report no correlation had a response rate below $35 \%$. Contradictory evidence was also identified regarding the influence of childbirth expectations on women's birth experience (Czarnocka \& Slade, 2000; Ayers et al., 2007; Leeds and Hargreaves, 2008; Goodman et al., 2014). Methodological issues were found when examining the impact of previous traumatic experiences. Most of the studies (Cohen et al., 2004; Edworthy et al., 2008; Leeds \& Hargreaves, 2008; Ford et al., 2010) collected data by asking women to select possible traumatic events from a pre-defined list which assumes that the event was associated with a trauma-related response. Finally, contrary evidence in the relationship between parity (Czarnocka \& Slade, 2000; Cohen et al., 2004; Olde et al., 2005; Davies et al., 2008; Boorman et al., 2014) and subsequent pregnancies (Czarnocka \& Slade, 2000; Carlander et al., 2014), with women's subjective perception of birth and PTSS was evident. These findings thereby suggest that factors which influence the birth and PTSS may differ or that other important factors were not assessed.

\section{Discussion}

This review aimed to identify the psychosocial factors that could contribute to, or be influenced by women's subjective accounts of childbirth. Following careful analysis of the included studies, it appears that there are some vulnerability factors in pregnancy and risk factors during birth which can increase the likelihood of experiencing a negative birth or develop PTSS (predictor variables). Furthermore, this review has identified that some implications in the postnatal period are possible following a negative birth experience or as a cause of PTSD (outcome variables). There also appears to be some protective factors identified during pregnancy or in labour (predictor variables) which promote a more positive childbirth experience.

\section{Predictor variables}


Predictor variables which represent a vulnerability for a negative birth, development of PTSS or

Associations between women's subjective experiences of birth and development of PTSD due to childbirth have been identified previously (Ayers et al., 2016). This may imply that risk factors for both a traumatic birth experience and for PTSS are similar since childbirth trauma is a precursor to PTSD. 
A number of the risk factors for PTSD following childbirth identified in this review have also been highlighted in two meta-analyses (Grekin \& O’Hara, 2014, Ayers et al., 2016). Similar to this review, highlighted risk factors for PTSD in community samples discussed by Grekin and O'Hara (2014) included support from staff during labour, pregnancy psychopathology and history of psychopathology, increased level of pain during labour, a history of trauma and decreased level of perceived control during labour. Ayers et al., (2016) report that depression during pregnancy, a history of PTSD and counselling during pregnancy, lack of support during birth and dissociation were the factors with the strongest associations with PTSD.

\section{Outcome variables}

The most commonly examined outcome variable in the selection of studies from this review is PND. This review found that a negative birth experience increases the risk of PND and that a high degree of comorbidity exists between PTSD and PND. This is similar to reports by Grekin and O'Hara (2014) and Ayers et al., (2016) whom both indicated that PND had the strongest association with PTSD among all variables. Other psychological outcome variables which were less commonly examined include PTSD, anxiety in the postnatal period and fear of childbirth. This review suggests that women who have a negative birth experience are at an increased risk of developing these psychiatric morbidities and other psychological concerns.

Social outcome variables were also examined, and different findings were reported. Studies in this review indicate that women's subjective interpretation of the birth experience can influence both maternal-infant attachment and the perception of the infant. In contrast, PTSD was not found to affect maternal-infant attachment (Ayers et al., 2007). The couple's relationship and parenting were not considered to be influenced by either the birth experience or PTSD. However, the quality of the couple's relationship was not measured prior the birth, therefore, subtle changes in quality as a result of the birth and/or PTSD onset may have been missed. Finally, while one study (Czarnocka \& Slade, 2000) suggests 
that PTSD may influence the decision to have future children, women's perception of the birth experience appears to play no role (Carlander et al., 2014). The postnatal care that women receive may alter these findings, and hence, the context of the studies should be considered before reaching conclusions.

Findings reported in this review also resonate the available qualitative literature. A meta-synthesis by Fenech and Thomson (2014) into the psychosocial implications of a traumatic birth Identified how women were tormented by intense negative emotions, nightmares and flashbacks; experienced shattered relationships with their infant and partner, and experienced a sense of loss as they decided not to have future children due to fear of childbirth. Elmir et al., (2010) similarly report how the traumatic birth left women experiencing a roller-coaster of emotions including anxiety, depression, and suicidal thoughts, felt trapped due to the nightmares and flashbacks they had to endure and suffered disrupted relationships both through disconnection with their baby and not wanting to be touched by their partner again.

Apart from the complex and contradictory data identified within the predictor and outcome variables, which make it difficult to draw conclusions, additional insights are prominent from this review. First of all, the review highlights a scarcity of literature that explores positive or even neutral childbirth experiences; with the majority of literature focusing on risk factors and outcomes of negative and traumatic birth, and PTSD. The pathological focus within the research literature echoes wider sociocultural messages, such as negative portrayals of childbirth in visual media and social networks, including portrayals of the female body as one that is inferior and requires technology to birth (Morris \& McInenrey, 2010) and a focus on birth as risky, dramatic and painful (Luce et al., 2016). Shifting towards wellbeing ('salutogenic') perspective for psychological studies of childbirth could enable a more comprehensive understanding of how women can stay in good health despite a distressing birth experience. While some evidence such as support and increased control during labour has already been 
identified as influences of positive childbirth experiences (Goodman et al., 2004), other elements such as positive personality traits and wellbeing have not been explored.

Secondly, most of the variables, including personality traits, which have been highlighted in this review are negative and do not capture the range of emotions, beliefs, characteristics and experiences that women can experience during the perinatal period. A salutogenic perspective is required to have a more thorough understanding of how women can stay in good health despite a distressing birth experience. Studies with a salutogenic focus in the general health literature have demonstrated that individuals with an above-average sense of coherence (SOC) significantly mitigate the influence of a stressful life event on their self-reported health (Richardson \& Ratner, 2005). Therefore, exploring women's SOC could help to enhance our understanding of how positive factors impact on the birth experience and women's subjective interpretations of such, as well as their association with outcomes. SOC enables women to make life events meaningful, comprehensible and manageable through the use of a range of general resistance resources (GRRs) at their disposal. Several links between the variables identified in this review and GRRs can be identified, namely through identity (personality traits), social support and family ties (relationships), knowledge and intelligence (expectations) and commitment (control). Therefore, due to the associations present between these GRRs (or the lack of) and negative birth experiences and PTSD, it is only vital that their presence is explored in light of more positive aspects of the birth. Additionally, further GRRs can be explored that can potentially influence women's subjective appraisal of the birth experience, such as a preventative health orientation (positive mental well-being). An in-depth understanding of how SOC and GRRs impact women in their subjective appraisal of the birth and the outcomes of such will further enable health professionals to adopt more appropriate, individually centred care.

Finally, this review identified that there are different influencing factors between PTSD and negative or traumatic birth experience. For instance, parity, having unmet expectations, increased pain perception and loss of control were associated with a traumatic birth but not with the development of PTSD (Czarnocka \& Slade, 2000; Cohen et al., 2004; Goodman et al., 2004; Ayers et al., 2007; Leeds and 
Hargreaves, 2008; Weisman et al., 2010; Larsson et al., 2011). Following the birth of their baby, the

A key limitation is the inclusion of studies which focus on PTSD, on the premise that women who develop PTSD, would have experienced a traumatic birth (Yildiz et al., 2017). However, it became apparent that it is possible that these women were misdiagnosed and were suffering from PND, anxiety and postpartum stress, particularly since an important criterion of PTSD (whether women experienced actual or threatened death or serious injury and experienced intense fear, helplessness, or horror) was not examined. This could imply that women who were misdiagnosed with PTSD never had a traumatic birth, making their inclusion in this study inappropriate. This also makes it difficult to determine the identified predictors are caused by trauma or an effect of PTSD. Additionally, not all language studies were included as the translation of such studies was not possible due to time constraints. Due to the 
different psychometric properties of the tools that were used in the included studies, certain findings need to be interpreted with caution as comparisons were made between outcomes from validated and non-validated tools. Finally, as the majority of the studies which met the inclusion criteria took a pathological lens, it is difficult to obtain a more coherent picture to understand childbirth experiences.

\subsection{Recommendations}

This review presents some recommendations for research. Primarily, further research is required to understand different birth experiences since currently, the focus is on negative and traumatic birth. Secondly, this review has highlighted that the risk factors and implications of traumatic birth and PTS are correlated but not necessarily the same, as such, these should be explored separately. Additionally, since not all women who report a negative or traumatic birth develop PTSD, it is worth exploring what is preventing these women from developing PTSD and identify the protective factors involved.

\section{Conclusion}

This review has identified psychosocial variables which have been used by authors to assess associations with women's subjective perceptions of their birth experience. Contradictory evidence has been identified which make it difficult to draw meaningful conclusions, although tools and methodologies may play a role. The dearth of literature exploring positive childbirth experiences and the different contributing factors of birth experiences are a cause for concern as they limit understanding of the birth experience and, therefore, warrant further exploration. Additionally, the comorbidity which exists between post-traumatic stress disorder and postnatal depression and the differences which exist between post-traumatic stress disorder and traumatic birth have also been highlighted in this review and require further consideration. What is evident is that there is a multitude of factors which are potentially linked with birth experiences and these need to be explored both from a pathogenic and salutogenic perspective. 


\section{Acknowledgements}

We would like to thank Dr Louise Hunt, $\mathrm{PhD}$ (University of Central Lancashire, Preston, UK) for her input in ensuring adequate quality appraisal of the considered articles for this review, your support is much appreciated. We would also like to acknowledge the help and support of Daniela Carabott, BSc, RM and Ruth Marie Xuereb, BSc, MSc RM (Mater Dei Hospital, Msida, Malta), for their input to ensure the success of this review.

\section{References}

Anderson, C. (2010). Impact of traumatic birth experience on Latina adolescent mothers. Issues in Mental Health Nursing, 31(11), 700-707. doi:10.3109/01612840.2010.518784

Antonovsky, A. (1987). Unraveling the mystery of health: How people manage stress and stay well. San Francisco, CA: Josey-Bass.

Ayers, S., Bond, R., Bertuilles, S., \& Wijma, K. (2016). The aetiology of post-traumatic stress following childbirth: A meta-analysis and theoretical framework. Psychological Medicine, 46(6), 11211134. doi:10.1017/S0033291715002706

Ayers, S., Harris, R., Sawyer, A., Parfitt, Y., \& Ford, E. (2009). Posttraumatic stress disorder after childbirth: Analysis of symptom presentation and sampling. Journal of Affective Disorders, 119(1), 200-204. https://doi.org/10.1016/j.jad.2009.02.029

Ayers, S., Jessop, D., Pike, A., Parfitt, Y., \& Ford, E. (2014). The role of adult attachment style, birth intervention and support in posttraumatic stress disorder after childbirth: A prospective study of incidence. Journal of Affective Disorders, 155, 295-298. 
Ayers, S., Wright, D. B., \& Wells, N. (2007). Symptoms of post-traumatic stress disorder in couples after birth: Association with the couple's relationship and parent-baby bond. Journal of Reproductive \& Infant Psychology, 25(1), 40-50.

Beck, C. (2004). Birth trauma: In the eye of the beholder. Nursing Research, 53(1), 28-35.

Bener, A., Gerber, L. M., \& Sheikh, J. (2012). Prevalence of psychiatric disorders and associated risk factors in women during their postpartum period: A major public health problem and global comparison. International Journal of Women's Health, 4, 191-200.

Bennington, L., K. (2010). The relationship among maternal infant bonding, spirituality, and maternal perception of childbirth experience . (2011163846).

Benoit, D. (2004). Infant-parent attachment: Definition, types, antecedents, measurement and outcome. Paediatric Child Health, 9(8), 541-545.

Bettany-Saltikov, J. (2012). How to do a systematic literature review in nursing: A step by step guide. Maidenhead: McGrawHill/Open University Press.

Boorman, R. J., Devilly, G. J., Gamble, J., Creedy, D. K., \& Fenwick, J. (2014). Childbirth and criteria for traumatic events. Midwifery, 30(2), 255-261.

Bryanton, J., Gagnon, A. J., Hatem, M., \& Johnston, C. (2008). Predictors of early parenting selfefficacy: Results of a prospective cohort study. Nursing Research, 57(4), 252-259.

Centre for Reviews and Dissemination, CRD. (2009). Systematic reviews: CRD's guidance for Undertaking reviews in health care. York: CRD, University of York.

Cohen, M. M., Ansara, D., Schei, B., Stuckless, N., \& Stewart, D. E. (2004). Posttraumatic stress disorder after pregnancy, labor, and delivery. Journal of Women's Health (15409996), 13(3), 315324. doi:10.1089/154099904323016473 
Creedy, D. K., Shochet, I., \& Horsfall, J. (2000). Childbirth and the development of acute trauma symptoms: Incidence and contributing factors. Birth, 27(2), 104-111.

Crowe, K., \& von Baeyer, C. (1989). Predictors of a positive childbirth. Birth, 16(2), 59-63.

Csikszentmihalyi, M. (1990). Flow: The psychology of optimal experience. New York: Harper \& Row.

Czarnocka, J., \& Slade, P. (2000). Prevalence and predictors of post-traumatic stress symptoms following childbirth. British Journal of Clinical Psychology, 39, 35-51.

Dahlberg, U., \& Aune, I. (2013). The woman's birth experience-the effect of interpersonal relationships and continuity of care. Midwifery, 29(4), 407-415. doi: 10.1016/j.midw.2012.09.006

Davies, J., Slade, P., Wright, I., \& Stewart, P. (2008). Posttraumatic stress symptoms following childbirth and mothers' perceptions of their infants. Infant Mental Health Journal, 29(6), 537-554.

de Von, H. A., Block, M. E., Moyle-WrighY, P., Ernst, D. M., Hayden, S. J., Lazzara, D. J., . . KostasPolston, E. (2007). A psychometric toolbox for testing validity and reliability. Journal of Nursing Scholarship, 39(2), 155-164.

Downe, S., Schmidt, E., Kingdon, C., \& Heazell, A. E. (2013). Bereaved parents' experience of stillbirth in UK hospitals: a qualitative interview study. BMJ open, 3(2), e002237.

Downe, S., Schmidt, E., Kingdon, C., \& Heazell, A. P. E. (2013). Bereaved parents' experience of stillbirths in UK hospitals: A qualitative interview study. BMJ Open, 3(2)10.1136/bmjopen-2012002237

Elmir, R., Schmied, V., Wilkes, L., \& Jackson, D. (2010). Women's perceptions and experiences of a traumatic birth: A meta-ethnography. Journal of Advanced Nursing, 66(10), 2142-2153. 
Fenech, G., \& Thomson, G. (2014). 'Tormented by ghosts from their pasts': A meta-synthesis to explore the psychosocial implications of a traumatic birth on maternal wellbeing. Midwifery, 30(2), 185193.

Ford, E., \& Ayers, S. (2011). Support during birth interacts with prior trauma and birth intervention to predict postnatal post-traumatic stress symptoms. Psychology and Health, 26, 1553-1570. doi:10.1080/08870446.2010.533770

Ford, E., Ayers, S., \& Bradley, R. (2010). Exploration of a cognitive model to predict post-traumatic stress symptoms following childbirth. Journal of Anxiety Disorders, 24, 353-359.

Georgsson Öhman, S., Saltvedt, S., Waldenström, U., Grunewald, C., \& Olin- Lauritzen, S. (2006). Pregnant women's responses to information about an increased risk of carrying a baby with Down syndrome. Birth, 33(1), 64-73.

Goodman, P., Mackey, M. C., \& Tavakoli, A. S. (2004). Factors related to childbirth satisfaction. Journal of Advanced Nursing, 46, 212-219.

Grekin, R., \& O'Hara, M. W. (2014). Prevalence and risk factors of posttraumatic stress disorder: A meta-analysis. Clinical Psychology Review, 34(5), 389-401. doi:10.1016/j.cpr.2014.05.003

Hill, E., \& Firth, A. (2018). Positive birth experiences: a systematic review of the lived experience from a birthing person's perspective.

Hofberg, K., \& Brockington, I. F. (2000). Tokophobia: An unreasoning dread of childbirth. A series of 26 cases. The British Journal of Psychiatry, 176, 20th October 2014.

Howard, L. M., Flach, C., Mahay, A., Sharp, D., \& Tylee, A. (2011). The prevalence of suicidal ideation identified by the edinburgh postnatal depression scale in postpartum women in primary care: Findings from the RESPOND trial. BMC Pregnancy and Childbirth, 11(57), 23rd October 2014. doi:10.1186/1471-2393-11-57 
Hsieh, Y. T., Chao, Y. M. Y., \& Shiao, J. S. C. (2013). A qualitative study of psychosocial factors affecting expecting mothers who choose to continue a cleft lip and/or palate pregnancy to term. Journal of Nursing Research, 21(1), 1-9.

Humenick, S. (2006). The life changing significance of normal birth. The Journal of Perinatal Education, 15(4), 1-3.

Jackson, R., Ameratunga, S., Broad, J., \& Connor, J. (2006). The GATE frame: Critical appraisal with pictures. ACP Journal Club, 144(2), A8.

Karlströml, A., Nystedt, A., \& Hildingsson, I. (2015) The meaning of a very positive birth experience: focus groups discussions with women. BMC Pregnancy and Childbirth, 15:251. Doi: 10.1186/s12884-015-0683-0.

Kelley, M. C., \& Trinidad, S. B. (2012). Silent loss and the clinical encounter: parents' and physicians' experiences of stillbirth-a qualitative analysis. BMC pregnancy and childbirth, 12(1), 137.

Klint Carlander, A., Andolf, E., Edman, G., \& Wiklund, I. (2014). Impact of clinical factors and personality on the decision to have a second child. longitudinal cohort-study of first-time mothers. Acta Obstetricia Et $\quad$ Gynecologica $\quad$ Scandinavica, 93(2), $\quad$ 182-188. doi:10.1111/aogs.12306

Larsson, C., Saltvedt, S., Edman, G., Wiklund, I., \& Andolf, E. (2011). Factors independently related to a negative birth experience in first-time mothers. Sexual \& Reproductive Healthcare: Official Journal of the Swedish Association of Midwives, 2(2), 83-89. doi:10.1016/j.srhc.2010.11.003

Leeds, L., \& Hargreaves, I. (2008). The psychological consequences of childbirth. Journal of Reproductive \& Infant Psychology, 26(2), 108-122. 
Luce, A., Cash, M., Huntley, V., Cheyne, H., van Teijlingen, E., \& Angell, C. (2016). "Is it realistic?" the portrayal of pregnancy and childbirth in the media BMC Pregnancy and Childbirth, 16, 40. doi:doi.org/10.1186/s12884-016-0827-x

Lukasse, M., Vangen, S., Øian, P., Kumle, M., Ryding, E. L., \& Schei, B. (2010). Childhood abuse and fear of childbirth--a population-based study. Birth (Berkeley, Calif.), 37(4), 267-274. doi:10.1111/j.1523-536X.2010.00420.x

Lundgren, I., Karlsdottir, S. I., \& Bondas, T. (2009). Long-term memories and experiences of childbirth in a nordic context - a secondary analysis. . International Journal of Qualitative Studies on Health and Well-being, 4(2), 115-128.

McDonald, S., Slade, P., Splby, H., \& Iles, J. (2011). Post-traumatic stress symptoms, parenting stress and mother-child relationships following childbirth and at 2 years postpartu. Journal of Psychosomatic Obstetrics and Gynecology, 32(3), 141-146.

Meades, R., \& Ayers, S. (2011). Anxiety measures validated in perinatal populations: A systematic review. Journal of Affective Disorders, 133(1-2), 1-5. doi:10.1016/j.jad.2010.10.009

Melender, H.L. (2006) What constitutes a good birth? A qualitative study of pregnant Finnish women. Journal of Midwifery and Women's Health, 51(5), 331-339.

Michels, A., Kruske, S., \& Thompson, R. (2013). Women's postnatal psychological functioning: The role of satisfaction with intrapartum care and the birth experience. Journal Or Reproductive and Infant Psychology, 31(2), 172-182.

Mittelmark, M. B., Sagy, S., Eriksson, M., Bauer, G. F., Pelikan, J. M., Lindström, B., \& Arild Espnes, G. (2017). The handbook of salutogenesis. Springer Nature. 
Morris, T., \& McInenrey, K. (2010). Media representations of pregnancy and childbirth: An analysis of reality television programs in the united states. Birth, 37(2), 134-140. doi:10.1111/j.1523536X.2010.00393.x

Navarro, P., Ascaso, C., Garcia-Esteve, L., Aquado, J., Torres, A., \& Martin-Santos, R. (2007). Postnatal psychiatric morbidity: A validation study of the GHQ-12 and the EPDS as screening tools. General Hospital Psychiatry, 29, 1-7.

Nichols, F. H. (1996). The meaning of the childbirth experience: A review of the literature. Journal of Perinatal Education, 5(4), 71-77.

Nilsson, L., Thorsell, T., Hertfelt Wahn, E., \& Ekström, A. (2013). Factors influencing positive birth experiences of first-time mothers. Nursing Research and Practice, , 19th October, 2014. doi:10.1155/2013/349124

O’Donovan, A., Alcorn, K. L., Patrick, J. C., Creedy, D. K., Dawe, S., \& Devilly, G. J. (2014). Predicting posttraumatic stress disorder after childbirth. Birth, 30(2), 935-941.

Obeidat, H. M., Bond, E. A., \& Clark Callister, L. (2009). The parental experience of having an infant in the newborn intensive care unit. The Journal of Perinatal Education, 18(3), 23-29. $10.1624 / 105812409 X 461199$

Olde, E., van der Hart, O., Kleber, R. J., van Son, M. J. M., Wijnen, H. A. A., \& Pop, V. J. M. (2005). Peritraumatic dissociation and emotions as predictors of PTSD symptoms following childbirth. Journal of Trauma \& Dissociation, 6(3), 125-142.

Perdok, H., Verhoeven, C. J., van Dillen, J., Schuitmaker, T. J., Hoogendoorn, K., Colli, J., Schellevis, F. G., ... de Jonge, A. (2018). Continuity of care is an important and distinct aspect of childbirth experience: findings of a survey evaluating experienced continuity of care, experienced quality of care and women's perception of labor. BMC pregnancy and childbirth, 18(1), 13. doi:10.1186/s12884-017-1615-y 
Skari, H., Skreden, M., Malt, U. F., Dalholt, M., Ostensen, A. B., Egeland, T., \& Emblem, R. (2002). Comparative levels of psychological distress, stress symptoms, depression and anxiety after childbirth--a prospective population-based study of mothers and fathers. BJOG: An International Journal of Obstetrics and Gynaecology, 109(10), 1154-1163.

Smith, V., Daly, D., Lundgren, I., Eri, T., BenstoeM, C., \& Devane, D. (2014). Salutogenically focused outcomes in systematic reviews of intrapartum interventions: A systematic review of systematic reviews. Midwifery, 30(4), e151-e156.

Tarkka, M. T., Paunonen, M., \& Laippala, P. (2000). Importance of the midwife in the first-time Mother's experience of childbirth. Scandinavian Journal of Caring Sciences, 14(3), 184-190.

Thomson, G. (2010). Psychology and labour experience: birth as a peak experience. In Essential midwifery practice: intrapartum care (p. 191). Wiley-Blackwell, Oxford.

Waldenström, U., Hildingsson, I., Rubertsson, C., \& Rådestad, I. (2004). A negative birth experience: Prevalence and risk factors in a national sample. Birth (Berkeley, Calif.), 31(1), 17-27.

Weisman, O., Granat, A., Gilboa-Schechtman, E., Singer, M., Gordon, I., Azulay, H., Feldman, R. (2010). The experience of labor, maternal perception of the infant, and the mother's postpartum mood in a low-risk community cohort. Archives of Women's Mental Health, 13(6), 505-513. doi:10.1007/s00737-010-0169-z

White, T., Matthey, S., Boyd, K., \& Barnett, B. (2006). Postnatal depression and post-traumatic stress after childbirth: Prevalence, course and co-occurrence. Journal of Reproductive \& Infant Psychology, 34(2), 107-120.

Wiegers, T.A. (2009. The quality of maternity care services as experienced by women in the Netherlands. BMC Pregnancy Childbirth, 9(18), 1471-2393. doi: 10.1186/1471-2393-9-18 
Yildiz, P. D., Ayers, S., \& Philips, L. (2017). The prevalence of posttraumatic stress disorder in pregnancy and after birth: A systematic review and meta-analysis. Journal of Affective Disorders, 208, 634-645. doi:10.1016/j.jad.2016.10.009

Zeanah, C. H., Danis, B., Hirshberg, L., Benoit, D., Miller, D., \& Scott Heller, S. (1999). Disorganized attachment associated with partner violence: A research note. Infant mental health journal, 20(1), $77-86$. 


\section{Figure 1}
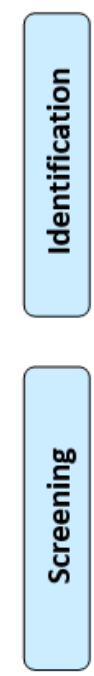

Articles added following citation/reference track $(n=43)$

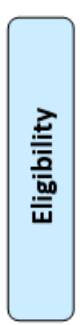

Records identified through database searching ( $n=10.115$ )

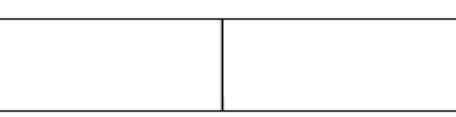

Records remaining after removing duplicates and articles whose abstract did not meet inclusion criteria ( $n=151)$

Full text not available ( $n=16)$
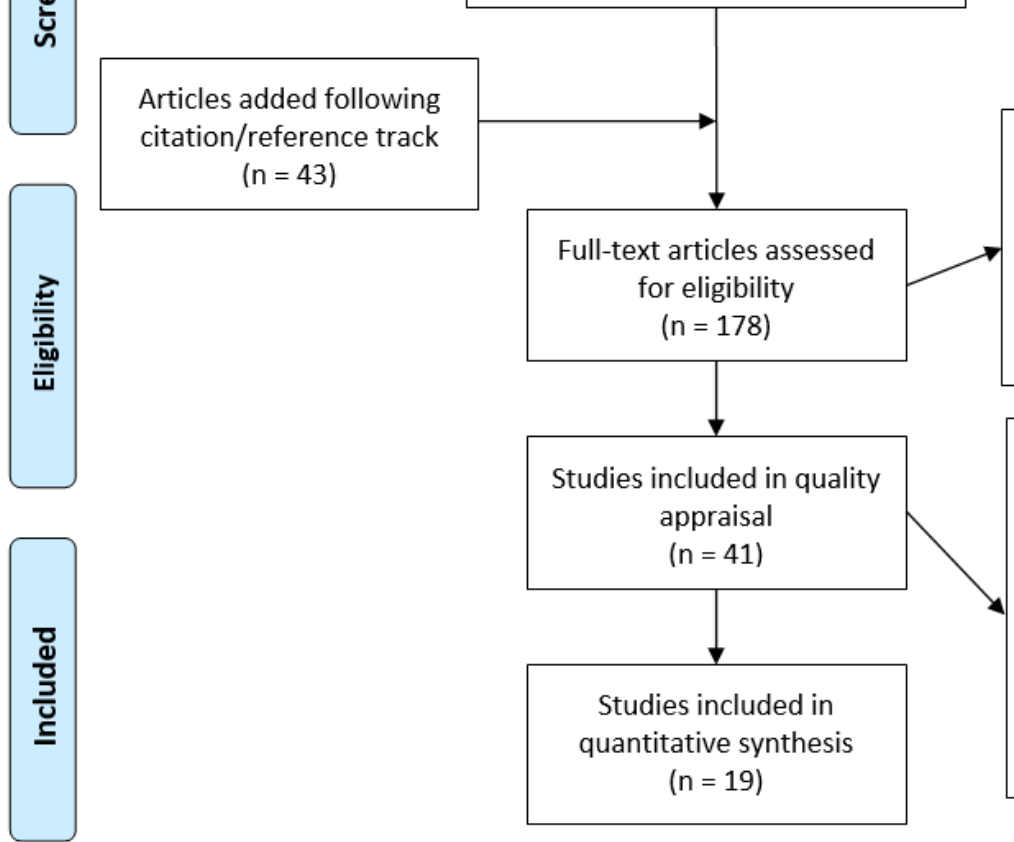

Full-text articles excluded as did not meet:

Participant criterion $(n=58)$

Exposure criterion $(n=24)$

Outcome criterion $(n=48)$

Type of study criterion $(n=7)$

\begin{tabular}{|c|c|}
\hline $\begin{array}{l}\text { Studies included in quality } \\
\text { appraisal } \\
(\mathrm{n}=41)\end{array}$ & $\begin{array}{l}\text { Articles excluded during } \\
\text { quality appraisal: } \\
\text { Majority of tools had poor } \\
\text { psychometric properties ( } \mathrm{n}=\end{array}$ \\
\hline$\downarrow$ & $\begin{array}{c}16) \\
\text { Review papers used for }\end{array}$ \\
\hline $\begin{array}{l}\text { Studies included in } \\
\text { quantitative synthesis } \\
(\mathrm{n}=19)\end{array}$ & $\begin{array}{l}\text { reference }(n=4) \\
\text { Review papers graded 'D’ in } \\
\text { quality appraisal }(n=2)\end{array}$ \\
\hline
\end{tabular}

Figure 1 - Prisma Diagram 

Click here to access/download

\section{Table}

THE CHILDBIRTH

EXPERIENCE_WomenBirth_Tables2.docx 


\section{Credit Author Statement}

Giliane McKelvin: Conceptualisation, methodology, formal analysis, investigation, data curation, writing original draft, writing - review \& editing, visualisation

Gill Thomson: conceptualisation, methodology, validation, writing - review \& editing, supervision

Soo Downe: methodology, verification, supervision

\section{Acknowledgement}

We would like to thank Dr Louise Hunt, PhD (University of Central Lancashire, Preston, UK) for her input in ensuring adequate quality appraisal of the considered articles for this review, your support is much appreciated. We would also like to acknowledge the help and support of Daniela Carabott, BSc, RM and Ruth Marie Xuereb, BSc, MSc RM (Mater Dei Hospital, Msida, Malta), for their input to ensure the success of this review.

\section{Conflict of interest}

The authors report no conflict of interest.

\section{Funding}

No funding was used for this review.

\section{Ethics}

Not applicable for this review. 


\section{Credit Author Statement}

Giliane McKelvin: Conceptualisation, methodology, formal analysis, investigation, data curation, writing original draft, writing - review \& editing, visualisation

Gill Thomson: conceptualisation, methodology, validation, writing - review \& editing, supervision

Soo Downe: methodology, verification, supervision 


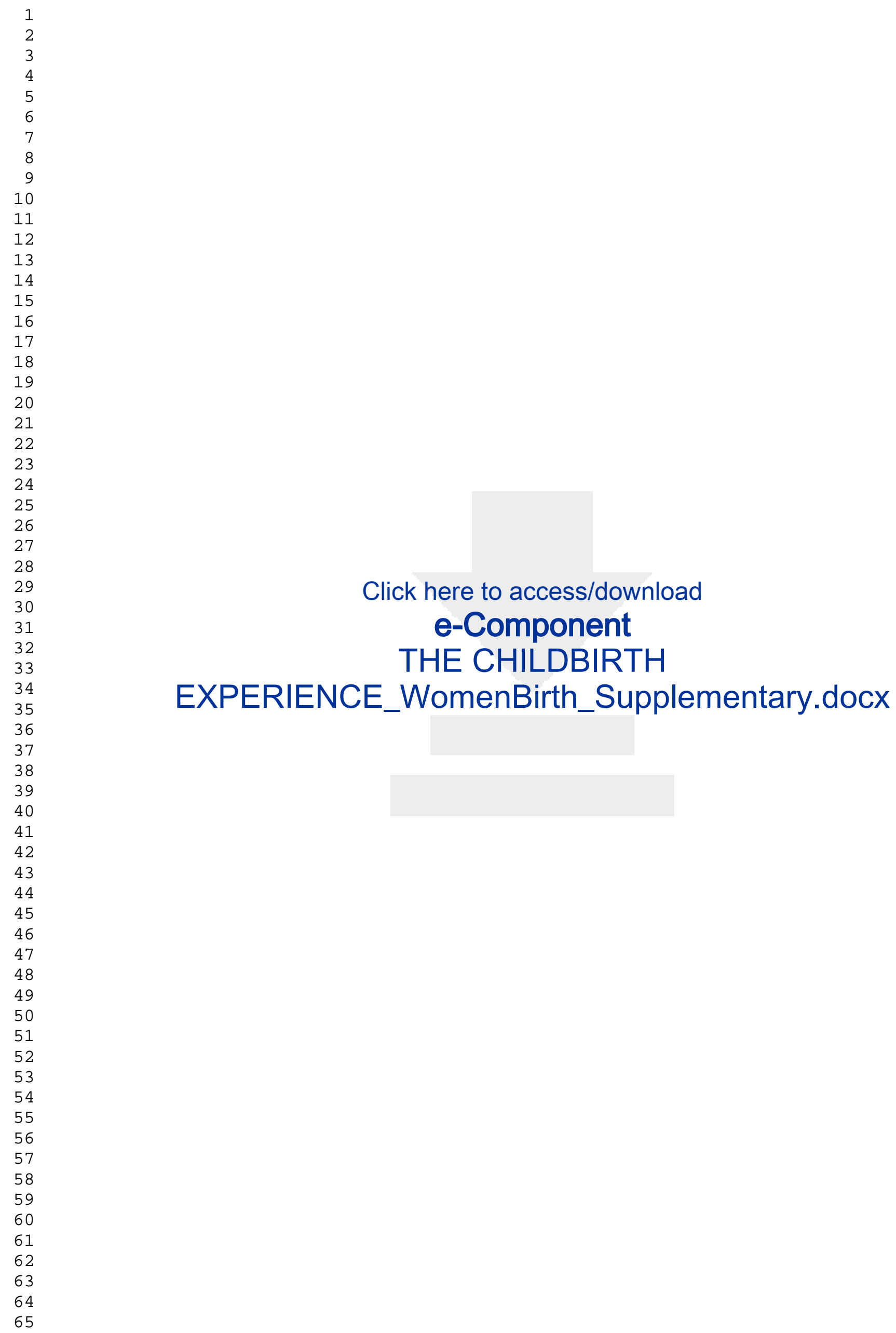

